\title{
The sugar tax - An opportunity to advance oral health
}

\author{
V. Wordley ${ }^{1}$, H. Lee ${ }^{1}$, M. Lomazzi ${ }^{2}$ and R. Bedi ${ }^{* 3}$
}

In brief

Highlights the new sugar tax and the need for the government to use some of the proceeds to make fluoridated toothpaste more affordable through tax exemption as a means of universal oral health prevention.
Emphasises the need to unite all healthcare professionals, school teachers and nurses in their joint responsibility to educate parents and children about the effects of sugar and the importance of fluoride toothpaste.
Calls for a significant proportion of the money raised from the sugar levy to be invested into innovative oral health education which directly integrates oral health with general health and wellbeing.

The new sugar tax was recently announced by Government, aiming to combat obesity through investment in school sports. Dental professionals should seize this rare opportunity to raise awareness of the other adverse effects of sugar; young children continue to suffer alarmingly high rates of dental cavities in the UK. A significant amount of money raised through the levy must be reinvested into ensuring fluoride toothpaste is more affordable. Since daily use of fluoride toothpaste is the most effective evidence-based oral health preventative measure that is widely used, this should receive tax exemption status from the government as a means of universal oral health prevention. There must also be a re-investment in innovative oral health education so that the next generation of children will alter their mind set about sugar. Oral health prevention advice must be tightly integrated into general health messages.

On March 8th 2017, Chancellor Philip Hammond announced the long-awaited sugar tax in his budget statement. ${ }^{1}$ The overriding aim is to combat obesity through investment into school sports. Time is now of the absolute essence for all dental professionals to ride this wave and campaign for some of this revenue to be directed towards improving the worsening situation for child oral health in the UK.

The scourge of sugar continues to attack children's teeth and disrupt their precious childhoods. The Faculty of Dental Surgery at the Royal College of Surgeons have recently released ever depressing figures showing a $24 \%$ rise in the number of tooth extractions performed on 0-4-year-olds in hospitals in England over the last decade. ${ }^{2}$

Tooth brushing with fluoridated toothpaste

${ }^{1}$ Consultant, Global Child Dental Fund, 26-29 Drury Lane, London, WC2B 5RL; 2 University of Geneva; ${ }^{3}$ Dental Institute, Division of Population and Patient Health, King's College London

${ }^{*}$ Correspondence to: Raman Bedi

Email: raman.bedi@kcl.ac.uk

Refereed Paper. Accepted 8 June 2017

DOI: 10.1038/sj.bdj.2017.572 is one of the most important interventions in the history of oral health. It is the key element in preventing and even reversing the initiation and progression of dental caries. According to the World Health Organisation, dental caries affects $60-90 \%$ of school children and nearly almost all adults. ${ }^{3}$ Untreated dental caries remains one of the most prevalent diseases negatively influencing speech, nutrition, growth and function, and social interactions. ${ }^{4}$ It disproportionately affects the overall health and well- being of poor and disadvantaged populations. Fluoride is therefore a critical vehicle to inhibit the demineralisation process and promote remineralisation to strengthen teeth in the entire population.

The evidence base for fluoride is significant. A comprehensive systematic review summarised the literature on fluoride toothpaste and concluded that: 'There is strong evidence that daily use of fluoride toothpaste has a significant caries preventive effect in children compared with placebo with prevented fraction of $24 \%{ }^{5}$ Another Cochrane review showed that in the meta-analysis result of 66 studies, the prevented fraction of decayed, missing, filled surface of teeth comparing to placebo ranged from $23 \%$ to $36 \%$ depending on the concentration of fluoride in toothpastes. ${ }^{6}$ A systematic review of economic evaluations of caries prevention also indicated that the cost effectiveness of fluoridated toothpaste is significant. ${ }^{7,8}$

Taken together, all these studies show the profound caries controlling effect of fluoridated toothpastes. Notably, the Centre of Disease Prevention and Control has classified the quality of evidence for fluoridated toothpastes at Grade 1 - the highest in the grading system used for determining the quality of evidence, showing the profound efficacy of fluoridated toothpaste in preventing dental caries. It is cost effective, publicly acceptable and already in widespread use, however, some families even in the UK are unable to afford quality fluoride toothpaste.

Alongside the newly introduced sugar tax, we therefore call for the Treasury to connect the dots between sugar and oral health and make fluoride toothpaste more affordable through tax exemption. We know that regular tooth brushing with fluoride toothpaste is a key pillar of optimal oral health prevention. 
Affordable fluoridated toothpastes can lessen the impact of the current oral disease epidemic and are an undeniably effective and easily implementable health investment for the government. In addition, there is a burgeoning market for non-fluoride toothpastes as patients take on more 'organic' approaches in a bid to be healthy. Many of these patients are not sufficiently aware about the strong evidence base of fluoride on caries prevention. We should be sending a clear message to the public that fluoride toothpaste is recommended by the government based on the current science - and the best way of doing this is by introducing a tax exemption on essential fluoride toothpaste, promoting universal oral health prevention for the whole population.

Globally, other essential prevention products such as vaccines, contraceptives and oral rehydration salts are tax exempted whereas fluoridated toothpaste prices remain high for many communities with various taxation. ${ }^{9}$ In African countries like Kenya and Zambia, the poorest $30 \%$ of population may need to work several days to buy one annual dose of toothpaste, which is around two tubes of toothpastes, at the lowest price. ${ }^{9}$ The U.K government should lead the way in actively demonstrating that oral health is an integral component of the primary health system. Prevention for dental caries must be both available and affordable to eradicate this silent epidemic.

The sugar tax will raise money to address the burden of obesity, but we also call for a significant proportion of the money raised from the sugar levy to be invested into innovative oral health communication with the public. Caregivers must be taught to remove themselves from the mindset that giving their children excess sugar is a sign of reward. High levels of sugar in the diet have an instantly damaging effect on teeth in addition to the myriad of other preventable medical conditions that no child should suffer from.

We must absolutely seize this rare and unique opportunity to fly the flag for oral health during the introduction of the sugar tax. We must unite with all other health professionals to permanently ingrain the sugar message. Health workers, school nurses and school teachers have key roles to play in educating parents and children about the effect of sugar on teeth and the importance of fluoridated toothpaste. If the government can also invest some of the tax proceeds towards powerful public communication and educational initiatives for oral health messages, obesity rates are expected to improve concurrently. Oral health education needs significant and innovative investment in tandem with other health messages. Implementing fiscal policies such as tax exemptions on fluoridated toothpaste is a powerful tool to enable improvements in health and wellbeing.

Ultimately, oral health is an integral part of overall health. We simply cannot delay any further in providing universal oral health prevention for absolutely everybody.

1. Forster K. New sugar tax confirmed in fight to combat rising obesity. The Independent. 2017. Available at http://www.independent.co.uk/news/uk/politics/budget2017-sugar-tax-philip-hammond-fight-obesity-childweight-gain-fizzy-drinks-a7618316.html (accessed June 2017).

2. Quinlan K. Oral health figures are a 'national scandal'. $\mathrm{Br}$ Dent J 2017; 222: 503.

3. World Health Organization. WHO Oral Health Fact sheet N³18. 2012 Available At http://www.who.int/ mediacentre/factsheets/fs318/en/ (accessed June 2017).

4. Institute of Medicine. Advancing Oral Health in America. Washington, DC: The National Academies Press, 2011.

5. Twetma S. Caries prevention with fluoride toothpaste in children: an update. Eur Arch Paediatr Dent 2009; 10: 162-167.

6. Walsh T, Worthington H V, Glenny A, Appelbe P, Marinho V, Shi X. Fluoride toothpastes of different concentrations for preventing dental caries in children and adolescents. Cochrane Database Syst Rev 2010; 1 CD007868.

7. Källestål C, Norlund A, Söder B et al. Economic evaluation of dental caries prevention: a systematic review. Acta Odontol Scand 2003; 61: 341-346.

8. Manau C, Cuenca E, Martínez-Carretero J, Salleras L. Economic evaluation of community programs for the prevention of dental caries in Catalonia, Spain. Community Dent Oral Epidemiol 1987; 15: 297-300.

9. Goldman A S, Yee R, Holmgren C J, Benzian H. Global affordability of fluoride toothpaste. Global Health 2008; 4: 7. 